\title{
Serum complement (C3, C4) levels in patients with acute myocardial infarction and angina pectoris
}

\author{
A.S.M. Giasuddin ${ }^{1}$, Jamila M. ElMahdawi ${ }^{1}$ and Fakhri M. ElHassadi ${ }^{2}$ \\ Departments of ${ }^{1}$ laboratory Medicine and ${ }^{2}$ Internal Medicine, Al-Arab Medical University, \\ Benghazi, Libya.e-mail: asmgias@proshikanet.com
}

\begin{abstract}
Serum complement (C3, C4) levels in Libyan patients with acute myocardial infarction (AMI; 31 patients) and angina pectoris (AP; 11 patients) at the $1^{\text {st }}$ day and $7^{\text {th }}$ day of attack were estimated. A group of 26 healthy Libyans were taken as control subjects (CS). Serum C3 and C4 levels (mean \pm SD, $\mathrm{mg} / \mathrm{dl}$ ) were elevated at the $1^{\text {st }}$ day in AMI as well as AP patients (C3 $\rightarrow$ AMI1: $154.0 \pm 28.5$, AP1: $152.0 \pm$ 45.0, CS: $132.0 \pm$ 8.0, ANOVA: p=0.0072; C4 $\rightarrow$ AMI1: $38 \pm 13$, AP1: $37 \pm$ 17, CS: $29 \pm 6$, ANOVA: $\mathrm{p}=0.0160$ ). No significant differences for the elevated $\mathrm{C} 3$ and $\mathrm{C} 4$ levels at the $1^{\text {st }}$ day were observed between the two diseases groups (AMI1 vs AP1 $\rightarrow$ C3: $p=0.879, C 4: p=0.818$ ). At the 7th day, C3 and C4 levels were further elevated in AMI, while they remained at the similar elevated levels in AP $(\mathrm{C} 3 \rightarrow$ AMI 7: $173.1 \pm 28.0$, AP 7: $149.0 \pm$ 41.0, CS: $132.0 \pm 8.0$, ANOVA: $\mathrm{p}=0.0000$; C4 $\rightarrow$ AMI 7: $46.0 \pm 7.0$, AP 7: $36.0 \pm 15.0$, CS: $29.0 \pm 6.0$, ANOVA: p=0.0000). Again, no significance differences for the raised C3 and C4 levels at the $7^{\text {th }}$ day was observed between AMI and AP patients (AMI 7 vs AP $7 \rightarrow$ C3: $\mathrm{P}=0.059, \mathrm{C} 4: \mathrm{p}=0.06$ ). The C3 elevation showed significant positive correlation in AMI group $(\mathrm{r}=0.522, \mathrm{p}=0.003)$ while it was insignificant in AP patients $(\mathrm{r}=0.037$, $\mathrm{p}=0.915)$. Regarding C4 levels, it was significantly correlated in AMI ( $\mathrm{r}=0.483, \mathrm{p}=0.006)$, and in AP, although it was positively correlated $(r=0.656, \mathrm{P}=0.028)$ the observed difference was not significant $(\mathrm{t}=0.29, \mathrm{p}=0.778)$. In conclusion, serum C3 and C4 levels were more profoundly elevated in AMI compared to AP patients suggestive of an acute phase and inflammatory response.
\end{abstract}

\section{Introduction}

Acute myocardial infarction (AMI) is one of the major causes of death worldwide and atherosclerosis overweighs all other aetiologies ${ }^{1-3}$. Many immunological changes and probable mechanisms such as basophils, immunoglobulin E (IgE), complements, neutrophil activation, immunoglobulin G (IgG) and T-lymphocytes have been implicated in the aetiopathogenesis of $\mathrm{AMI}^{4-8}$. The complement system is believed to play an important role in the pathogenesis of ischemia induced myocardial damage. Activated components of complement are potent chemotactic and stimulatory agents for neutrophil and hence initiate infiltration into the extravascular myocardial tissue. It has been reported that substances present in the mitochondria-rich subcellular fractions of heart muscle can activate both the classical and alternative pathway ${ }^{9}$.

The complement derived anaphylatoxins, C3a and C5a, may themselves contribute to the cardiac dysfunction accompanying myocardial ischemia. C3a, apart from eliciting chemotaxis, enhances vascular permeability and provokes the release of mediators such as histamine, leukotriene, prostaglandins and platelet activating factor and also produces coronary constriction ${ }^{9}$. The formation of membrane attack complex (MAC) from complement was associated with loss of CD59 (protectin), an important sacrolemmal regulator of MAC, from infarcted area ${ }^{10}$. Thrombolytic therapy, with streptokinase (SK) and recombinant tissue type plasminogen activator (rTPA), activate the classical complement pathway and plasmin could be the common trigger for this phenomenon. A significant activation of the complement common pathway (from C3 to terminal components) was observed only with SK infusion and is attributable to the rapid formation of immunocomplex between SK and anti SK antibodies present in plasma as a consequence of previous streptococcal infections ${ }^{11}$.

Serum complement level has been found to be retrospectively associated with the presence of diffuse atherosclerosis, and it was asserted that high serum C3 level is a predictive of future myocardial 
infarction in male individuals who have no previous ischemic events ${ }^{12}$. Among patients dying suddenly from early infarction, no consumption of complement could be detected and $\mathrm{C} 3$, in particular, was significantly elevated in cases of coronary fatalities ${ }^{13}$. Literature survey indicated that no work was done or reported on serum complement levels in Libyan patients with AMI and AP. The present study on serum levels of C3 and $\mathrm{C} 4$ was therefore undertaken during the $1^{\text {st }}$ day of attack and at $7^{\text {th }}$ day after attack in Libyan patients with AMI and angina pectoris (AP) and healthy control subjects (CS) for comparison.

\section{Materials and Methods}

A total of 31 AMI patients (sex: 27 males, 4 females; age range: 36-80 years with mean age 62 years) were obtained from Coronary Care Unit (CCU) at Seventh October Hospital, Benghazi, Libya and Jamahiriya Hospital, Benghazi, Libya during September to December 1998. The diagnosis of AMI was based on clinical assessment (medical history, ECG changes) and laboratory evaluation with serial determination of cardiac enzymes $^{13-15}$. A group of 11 admitted AP cases were included as the disease control group (sex: 6 males, 5 females; age range: 48-88 years, with mean age 61 years). Their diagnosis was based on medical history and ECG changes ${ }^{13-15}$. According to the personal questionnaire, none of the AMI and AP patients were atopic, i.e., none had personal or family history of asthma, eczema, allergic rhinitis, drug allergy and/or food allergy and none had any connective tissue disorder. A group of 26 randomly selected clinically healthy Libyan adults were included in the study as control subjects (CS) (sex: 16 males, 10 females: age range: 38-82 years with mean age 58 years). All CS subjects were non smokers and had no history of allergic disorders.

Venous blood specimen was collected in tube with or without anticoagulant as required for routine hematological tests and biochemical investigations and special immunological assays. Blood specimens were allowed to clot at room temperature for 30 minutes and sera were separated by centrifugation at 2,500 rpm for 12-15 minutes. The separated sera were aliquoted and kept frozen at $-30^{\circ} \mathrm{C}$ until analyzed for the parameters of interest during the $1^{\text {st }}$ day of attack and at $7^{\text {th }}$ day after attack.

Complements (C3, C4) assay: Serum C3 and C4 levels were quantitatively assayed by using commercially available immuno kit of BioMerieux, France (Cat.No. C3: 714012A, C4: 720372A) based on the principle of radial immunodiffusion as described by Mancini et al ${ }^{16}$.

Statistical analysis: The statistical significance of the results was evaluated by Student's t-test, Paired t- test, One-way analysis of variance (ANOVA) and correlation coefficients ${ }^{17}$. All computing analyses were done using statistical package for social sciences (SPSS) programme.

\section{Results}

Table 1 shows the mean \pm SD values of serum C3 and C4 levels at the $1^{\text {st }}$ and $7^{\text {th }}$ day in AMI and AP patients and in CS together with observed range, 95\% CIM, ANOVA and Student's t-test.

The increased C3 levels at the $1^{\text {st }}$ day of heart attack in AMI patients (mean: $154 \mathrm{mg} / \mathrm{dl}$ ) were highly significant compared with CS individuals $(p=0.000)$. The elevation in C3 among AP patients at the $1^{\text {st }}$ day (mean: $152 \mathrm{mg} / \mathrm{dl}$ ) were also significant when compared with CS group $(p=0.03)$, while there was no significant difference for the elevated C3 levels between AMI and AP patients $(\mathrm{P}=0.879)$. At the $7^{\text {th }}$ day the elevation in C3 levels in AMI patients (mean: $171 \mathrm{mg} / \mathrm{dl}$ ) was still highly significant compared with CS subjects $(\mathrm{p}=0.000)$ and high C3 levels in AP patients (mean: $149 \mathrm{mg} / \mathrm{dl}$ ) was significant when compared with CS group $(\mathrm{p}=0.039)$. Again there was no significant difference in C3 levels at the $7^{\text {th }}$ day between AMI and AP patients $(p=0.059)$. In AMI group, C3 elevation at the $7^{\text {th }}$ day was significantly higher than that in the $1^{\text {st }}$ day $(\mathrm{t}=-3.39, \mathrm{p}=0.002)$ and there were significant positive correlation $(\mathrm{r}=0.522$; $\mathrm{P}=0.003$ ), while in case of AP patients the difference in increment of C3 levels at the $1^{\text {st }}$ and $7^{\text {th }}$ day were insignificant $(t=0.17, \mathrm{p}=0.871)$ and not correlated significantly $(\mathrm{r}=0.037, \mathrm{p}=0.915)$.

Regarding C4 at the $1^{\text {st }}$ day, it was observed that high C4 level in AMI patients (mean: $38 \mathrm{mg} / \mathrm{dl}$ ) was highly significant compared with CS subjects $(p=0.002)$. The elevated C4 level in AP patients (mean: $37 \mathrm{mg} / \mathrm{dl}$ ) was significant compared with CS subjects $(p=0.047)$ and there was no significant difference in C4 levels between AMI and AP patients $(\mathrm{p}=0.818)$. At the $7^{\text {th }}$ day, the elevation of C4 levels among AMI patients (mean: $46 \mathrm{mg} / \mathrm{dl}$ ) were highly significant in comparison with CS $(\mathrm{p}=0.000)$; the elevated C4 level in AP patients (mean: $36 \mathrm{mg} / \mathrm{dl}$ ) failed to reach to significant level compared with AMI patients $(\mathrm{p}=0.06)$ and CS subjects $(p=0.062)$. There was low positive correlation between C4 levels in AMI patients at the $1^{\text {st }}$ day and $7^{\text {th }}$ day $(\mathrm{r}=0.483 ; \mathrm{p}=0.006)$ and the 
Table I: Serum levels of C3 and C4 in AMI patients, AP patients at the 1st and 7th day and control subjects

\begin{tabular}{|c|c|c|c|c|c|c|c|c|}
\hline \multirow{2}{*}{$\begin{array}{c}\text { Statistical } \\
\text { Analysis }\end{array}$} & \multicolumn{4}{|c|}{ C3 level (mg/dl) } & \multicolumn{4}{|c|}{ C4 level (mg/dl) } \\
\hline & AMI $(n=31)$ & AP $(n=11)$ & CS $(n=26)$ & ANOVA: F(P) & AMI (n=31) & AP $(n=11)$ & $\operatorname{CS}(n=26)$ & ANOVA: $\mathrm{F}(\mathrm{P})$ \\
\hline \multicolumn{9}{|l|}{$1^{\text {st }}$ day analysis } \\
\hline Observed range & $69-210$ & $99-240$ & $116-146$ & & $9-67$ & $8.5-62$ & $16-43$ & \\
\hline Mean \pm SD & $154 \pm 28.5$ & $152 \pm 45$ & $132 \pm 8$ & $5.3284(0.007)$ & $38 \pm 13$ & $37 \pm 17$ & $29 \pm 6$ & $4.4086(0.016)$ \\
\hline 95\% CIM & $144-165$ & $122-183$ & $129-135$ & & $33-43$ & $26-48$ & $26-32$ & \\
\hline \multicolumn{9}{|l|}{$7^{\text {th }}$ day analysis } \\
\hline Observed range & $111-219$ & $87-201$ & $116-146$ & & $9-69$ & $8.5-59$ & $16-43$ & \\
\hline Mean \pm SD & $171 \pm 28$ & $149 \pm 41$ & $132 \pm 8$ & $16.950(10.000)$ & $46 \pm 15$ & $36 \pm 15$ & $29 \pm 6$ & $13.4126(0.000)$ \\
\hline 95\% CIM & $161-181$ & $122-177$ & $129-135$ & & $40-51$ & $26-46$ & $26-32$ & \\
\hline & \multicolumn{4}{|c|}{ Student's t-test } & \multicolumn{4}{|c|}{ Student's t-test } \\
\hline Groups & t value & & $\mathrm{df}$ & $\mathrm{P}$ & t value & & df & $\mathrm{P}$ \\
\hline \multicolumn{9}{|l|}{$1^{\text {st }}$ day analysis } \\
\hline AMI vs CS & 3.85 & & 55 & 0.000 & 3.20 & & 55 & 0.002 \\
\hline AMI vs AP & 0.15 & & 40 & 0.879 & 0.24 & & 40 & 0.815 \\
\hline AP vs CS & -2.26 & & 35 & 0.03 & -2.06 & & 35 & 0.047 \\
\hline \multicolumn{9}{|l|}{$7^{\text {th }}$ day analysis } \\
\hline AMI vs CS & 6.86 & & 55 & 0.000 & 5.39 & & 55 & 0.000 \\
\hline AMI vs AP & 1.95 & & 40 & 0.059 & 1.94 & & 40 & 0.06 \\
\hline AP vs CS & -2.14 & & 35 & 0.039 & -1.93 & & 35 & 0.062 \\
\hline
\end{tabular}

AMI: Acute myocardial infarction patients; AP: Angina pectoris patients; CS: Healthy control subjects: SD: Standard deviation; 95\% CMI: 95\% confidence interval for mean; ANOVA: One-way analysis variance; P: Probability; P $\leq 0.05$ : Significant; P>0.05: Not significant.

higher C4 levels at $7^{\text {th }}$ day reached a significant difference in comparison with the elevated C4 level at the $1^{\text {st }}$ day. (t: $\left.-3.01 ; \mathrm{p}=0.005\right)$. In AP patients C4 levels at the $1^{\text {st }}$ day and $7^{\text {th }}$ day were positively correlated ( $\mathrm{r}=0.656, \mathrm{p}=0.028$ ) and the observed difference was not significant $(\mathrm{t}=0.29, \mathrm{p}=0.778)$.

\section{Discussion}

We observed that the common complement component C3 and classical pathway complement component C4 were elevated in almost all patients in the $1^{\text {st }} 24$ hours post AMI and the elevations were significantly more pronounced one week after. The complement components increment was also found in AP patients, although in lesser extent, at the $1^{\text {st }}$ day post ischemic event. In contrary to AMI, there was a non significant decline in C3 and C4 at $7^{\text {th }}$ day compared with $1^{\text {st }}$ day among AP patients.

Although some studies had demonstrated in vivo deposition of complement components including MAC in the myocardium of patients with AMI, others could not detect any significant complement changes in the plasma of uncomplicated AMI patients ${ }^{18-20}$. It was explained that such activation at ischemic area might not cause detectable levels of complement catabolic peptides in peripheral circulation. The discrepancies between the above mentioned studies might be related to differences in the severity of the clinical situation of AMI patients in each occasion ${ }^{20}$. The substantial C3 and C4 increments in the $1^{\text {st }}$ week of AMI in our study could be a result of persistence of the stimulus via irreversible infarcted tissue, while the backtracked C3 and C4 values in AP patients at the $7^{\text {th }}$ day might be explained by lack of induction due to repair of reversible ischemic insult of myocardium. Another possible mechanism of complement activation in AMI includes the formation of oxygen radicals leading to the activation of $\mathrm{C5}$ by converting $\mathrm{C} 5$ to a $\mathrm{C} 5 \mathrm{~b}$ - like metabolite which then reacts with C6 and initiates MAC formation ${ }^{21}$. Complement activation also could be initiated by infusion of thrombocytic agents, although the patterns of complement activation were different in different drugs. Streptokynase (SK) activates the entire system through the classic pathway and recombinant tissue-type plasminogen activator (rTPA) gives a similar degree of activation of the classic pathway component $\mathrm{C} 4$, but only slightly activates $\mathrm{C} 3$ and the terminal components from C5 through $\mathrm{C}^{9}$.

Complement activation might lead to myocardial injury through the formation of MAC and the generation of anaphylatoxins as indicated in many studies $^{22-27}$. These studies demonstrated the relationship between morphological and functional alterations brought about by the assembly of MAC on myocardial cells. Recombinant soluble complement receptor type 1 (sCR1) could prevent membrane deposition of MAC in an animal model and coincidentally, there was preservation of 
myocardial ultrastructure and contractile function ${ }^{26}$, 27 . The hypothesis of anaphylaxis had been investigated and the results were consistent with the idea that resident cardiac mast cell activation might be involved in this phenomenon ${ }^{24}, 25$. In vitro induction of human heart mast cell degranulation by recombinant human $\mathrm{C} 5 \mathrm{a}$ anaphylatoxin had been provoked ${ }^{28}$. In animals the intracoronary injection of the anaphylatoxin (C5a) produced myocardial ischemia characterized by an increase in coronary vascular resistance, contractile dysfunction, a myocardial accumulation of leucocytes primarily neutrophils and a marked release of histamine into the coronary venous blood $^{24,29}$. Interestingly, the histamine release was not a contributory component to either the fall in contractile function or coronary blood flow alteration, since $\mathrm{H}_{1}$ and $\mathrm{H}_{2}$ histamine receptor blockade did not modify the $\mathrm{C} 5 \mathrm{a}$ induced myocardial infarction ${ }^{24,25}$. Instead C5a induced myocardial injury was dependent on the production of TxA2, leukotriene (LT), C4 and LTD4 ${ }^{30}$. Furthermore, prior treatment with Lodoxamide tromethamine, a mast cell inhibitor, attenuated the C5a induced myocardial release of histamine and TxA2 into the coronary circulation and blunted the ischemic response ${ }^{24,25}$. In man, consequences of complement activation and markers of mast cell degranulation have to be detected in peripheral circulation and/or in local injured tissue to provide evidence of anaphylactic reaction in ischemic and necrotic myocardial tissue.

\section{Acknowledgements}

The authors would like to acknowledge gratefully the financial support of the Faculty of Medicine, Al-Arab Medical University, Benghazi, Libya. The authors would like to thank Mr. M. Moniruzzaman Khan, IT Section, Medical College for Women \& Hospital, Uttara Model Town, Dhaka 1230, Bangladesh for typing the manuscript.

\section{References}

1. Souhami RL, Moxhan J. Textbook of medicine. $2^{\text {nd }}$ ed. New York, Churchill Livingstone, 1994, pp 390-404.

2. Antman EM, Braunwald E. Acute myocardial infarction. In: Harrison's Principles of internal medicine. Fauci AS, Braunwald E, Isselbacher KJ, Wilson JD, Martin JB, Kasper DL, et al (eds). $14^{\text {th }}$ ed. New York, McGraw Hill, 1998, pp 1352-65.

3. Pedersen ED, Waje-Andreassen U, Vedeler CA, Aamodt G, Mollnes TE. Systemic complement activation following human acute ischaemic stroke. Clin Exp Immunol. 2004; 137: 117-22.

4. Erdogan O, Gul C, Altun A, Ozbay G. Increased immunoglobulin $\mathrm{E}$ response in acute coronary syndromes. Angiology 2003; 54: 73-79.
5. Hannut R, Duchateau J, Mascart F, Staquet E, Vainsel $\mathrm{H}$, Bernard R. Value of serum immunoglobulin assays in early myocardial infarction. Pathol Biol Paris. 1992; 40: 632-37.

6. Schafer H, Mathey D, Hugo F, Bhakdi S. Deposition of the terminal C5b-9 complement complex infarcted areas of human myocardium. J Immunol. 1986; 137: 1945-49.

7. Takahashi M, Masuyama J-I, Ikeda U, Kitagawa SI, Kasahara T, Saito M, Kano S, Shimada K. Effects of endogenous endothelial interleukin-8 on neutrophil migration across the endothelial monolayer. Cardiovasc Res. 1995; 29: 670-75.

8. Blum A, Sclarovsky S, Rehavia E, Shohat B. Level of T lymphocyte sub-population, interleukin 1 beta and soluable interleukin 2 receptor in acute myocardial infarction. Am Heart J. 1994; 127: 1226-30.

9. Lucchesi BR. Role of neutrophil in ischemic heart diseases pathophysiologic role in myocardial ischemia and coronary artery perfusion. In: Thrombosis and platelets in myocardial ischemia. Metha JL, Conti RC, Brest AN (eds). Philadelphia, FA Davis Company, 1987, pp 35-48.

10. Vakeva A, Morgan BP, Tikkanen I, Helin K, Laurila P, Meri S. Time course of complement activation and inhibitor expression after ischemic injury in rat myocardium. Am J Pathol. 1994; 144: 1357-68.

11. Agostoni A, Gardinali M, Frangi D, Cafaro C, Conciato L, Sponzilli C, Salvioni A, Cugno M, Cicardi M. Activation of complement and kinin systems after thrombolytic therapy in patients with acute myocardial infarction. A comparison between streptokinase and recombinant tissue-type plasminogen activator. Circulation 1994; 90: 2666-70.

12. Muscari A, Bozzoli C, Puddu GM, Sangiorgi Z, Dormi A, Rovinetti C, Descovich GC, Puddu P. Association of serum C3 levels with the risk of myocardial infarction. Am J Med. 1995; 98: 357-64.

13. Edston E, Hag-Hamstem MV. Immunoglobulin E, mast cell specific tryptase and the complement system in sudden death from coronary artery thrombosis. Int $\mathrm{J}$ Cardiol. 1995; 52: 77-81.

14. Ebringer A, Rosenbaum $M$, Pincus $N$, Doyle AE. Changes in serum immunoglobulin after myocardial infarction. Am J Med. 1971; 50: 297-301.

15. Holborow EJ, Reeves WG. Immunology in medicine: A comprehensive guide to clinical immunology. London, Academic Press, 1977, pp 573-80.

16. Mancini G, Carbonara AD, Heremans JF. Immunochemical quantitation of antigens by single radial immunodiffusion. Immunochem. 1965; 2: 23542.

17. Kirkwood BR. Essentials of medical statistics. $1^{\text {st }}$ ed. Oxford, Blackwell Scientific Publications, 1988.

18. Yasuda M, Takeuchi K, Hiruma M, Iida H, Tahara A, Itagane H, Toda I, Akioka K, Teragaki M, Oku H. The complement system in ischemic heart disease. Circulation 1990; 81: 156-63. 
19. Muscari A, Bozzoli C, Massarelli G, Puddu GM, Palareti G, Legnani C, et al. Complement components and fibrinogen: Correlations and association with previous myocardial infarction. Cardiology 1995; 86: 232-37.

20. Frangi D, Gardinali M, Conciato L, Cafaro C, Pozzoni L, Agostoni A. Abrupt complement activation and transient neutropnea in patients with acute myocardial infarction treated with streptokinase. Circulation 1994: 89: $76-80$

21. Shingu M, Nobunaga M. Chemotactic activity generated in human serum from the fifth components of complement by hydrogen peroxide. Am J Pathol. 1984: 117: 201-06.

22. Ember JA, Sanderson SD, Taylor SM, Kawahara M, Hugli TE. Biologic activity of synthetic analogues of C5a anaphylotoxin. J Immunol. 1992; 148: 3165-70.

23. Palikhe A, Sinisalo J, Seppänen M, Haario H, Meri S, Valtonen V, et al. Serum complement C3/C4 ratio, a novel marker for recurrent cardiovascular events. Am J Cardiol. 2007; 99: 890-95.

24. Ito BR, Engler RL, Bazle UD. Role of cardiac mast cells in complement C5a-induced myocardial ischemia. Am J Physiol. 1993; 264: H1346-54.
25. Arumugam TV, Shiels IA, Woodruff TM, Granger DN, Taylor SM. The role of the complement system in ischemia-reperfusion injury. Shock 2004; 21: 401-09.

26. Homeister JW, Satoh PS. Kilgore KS, Lucchesi BR. Soluble complement receptor type 1 prevents human complement mediated damage of the rabbit isolated heart. J Immunol. 1993; 150: 1055-64.

27. Iltumur K, Karabulut A, Toprak G, Toprak N. Complement activation in acute coronary syndromes. APMIS 2005; 113: 167-74.

28. Patella V, de Crescenzo G, Ciccarelli A, Marinò I, Adt M, Marone G. Human heart mast cells: A definitive case of mast cell heterogeneity. Int Arch Allergy Immunol. 1995; 106: 386-93.

29. Martin SE, Chenoweth DE, Engler RL, Roth DM, Longhurst JC. Complement C5a decreases regional coronary blood flow and myocardial function in pig: Implications for a granulocyte mechanism. Circ Res. 1988; 63: 483-91.

30. Ito BR, Roth DM, Engler RL. Thromboxane A2 and peptidoleukotrienes contribute to the myocardial ischemia and contractile dysfunction in response to intracoronary infusion of C5a. Circ Res. 1990; 66: 596607. 